\title{
Why and how should we use environmental enrichment to tackle stereotypic behaviour? ${ }^{\text {is }}$
}

\author{
G. Mason *, R. Clubb, N. Latham, S. Vickery \\ Animal Sciences Department, University of Guelph, Guelph, Ont. N1G 2W1, Canada
}

Available online 2 August 2006

\begin{abstract}
This paper summarises recent findings on the causation of stereotypic behaviours and other abnormal repetitive behaviours (ARBs) in captive animals: primarily motivational frustration and/or brain dysfunction, with possible contributory roles also being played by habit-formation and 'coping' effects. We then review the extent to which ARBs occur in zoos and similar, estimating that at least 10000 captive wild animals are affected worldwide. We argue for 'zero tolerance' of such ARBs, because stress and poor welfare raise ethical issues, while abnormal behavioural phenotypes and possibilities of impaired brain development challenge both the indirect (e.g. educational) and the direct, intrinsic conservation value of affected animals. We then consider five potential means by which ARBs may be tackled: genetic selection; pharmacological treatment; the reinforcement of alternative behaviours; punishment; and environmental enrichment. All except punishment have potentially useful roles to play, but enrichment is the preferred approach: it is most likely to tackle the problems underlying stereotypic behaviours, and thence to improve both welfare and behaviour with few unwanted side-effects. Nevertheless, in zoos, environmental enrichment to date has only had partial success, with no study managing to abolish ARBs in all its subjects-suggesting either that the enrichments currently being used are never quite optimal, or that by the time they are tackled, ARBs have become resistant to change. We suggest some ways in which the effectiveness of enrichments may be enhanced; propose that certain properties of ARBs may usefully help evaluate their likely 'treatability'; and emphasise that if improving welfare is more important than just reducing ARB, then additional measures are needed in order to first, reliably identify those individuals most at risk from poor welfare, and then, to fully evaluate the welfare impact of enrichments. This paper also emphasises, with examples, the enormous potential value of zoo-derived data for helping understand
\end{abstract}

\footnotetext{
This paper is part of the special issue entitled "Conservation, Enrichment and Animal Behaviour", Guest Edited by Dr. Ronald R. Swaisgood.

* Corresponding author. Tel.: +1 519824 4120x56804.

E-mail address: GMason@uoguelph.ca (G. Mason).
} 
how taxon, ecological niche, rearing history, and current housing together affect animals' responses to captivity.

(C) 2006 Published by Elsevier B.V.

Keywords: Abnormal behaviour; Stereotypic behaviour; Environmental enrichment; Animal welfare; Prevalence; Zoo animals

\section{Introduction}

In this review, we estimate the extent of stereotypic behaviours in wild animals kept in zoos and breeding centres; propose that these behaviours should be eliminated on both welfare and practical grounds; and argue that using enrichments is fundamentally the most appropriate way to achieve this. This paper builds on a recent publication by Mason and Latham (2004), but incorporates new findings and hypotheses from several contributed chapters in a forthcoming book on these behaviour patterns (Mason and Rushen, in press).

We start with definitions of terms. 'Stereotypies' or 'stereotypic behaviours' have long been inter-changeably defined as repetitive, unvarying and apparently functionless behaviour patterns (e.g. Mason, 1991a). However, how 'unvarying' an activity has to be for inclusion has long been a moot point, leading to debates as to what to label such behaviours as over-grooming, which involve quite variable motor patterns (Garner, in press-a,-b; Mason, in press-a; Mills and Luescher, in press). Mills and Luescher (in press) therefore proposed that 'stereotypic behaviour' be used as a broad catch-all term for all apparently functionless, repetitive behaviours, even when the exact motor patterns involved are flexible (reserving 'stereotypies' for a sub-class of more predictable forms caused by particular types of brain dysfunction; cf. Garner, in press-a). This suggestion has advantages, but leaves two problems unsolved. The first is that 'lack of function' is often hard to ascertain, and indeed some odd-looking stress-related repetitive behaviours do actually seem to have beneficial consequences (e.g. repetitive hand-flapping and other 'stims' in autistic humans; repetitive oral movements in some captive ungulates: reviewed Mason and Latham, 2004). The second problem is that these descriptive definitions cover an enormous range of activities. This includes some that are perfectly normal and unproblematic (e.g. a cat kneading a pillow, a foetus or baby sucking its thumb, a dog chasing a stick); and yet when people ask ' Is $X$ a stereotypy?' or 'Is Y stereotypic?', they typically do not mean 'Is that behaviour repetitive and apparently functionless?' but rather 'Does that individual have a problem?'. One of us (GM) has therefore suggested that this broad term 'stereotypic behaviour' be used instead to mean 'repetitive behaviour induced by frustration, repeated attempts to cope and/or C.N.S. (brain) dysfunction' (Mason, in press-a). This shifts the emphasis from mere appearance onto biological causation; allows some functional activities to be included; and also maps more closely onto what most people actually mean when using this term in practice. However, it brings with it a new challenge: sometimes we simply do not know the cause. This is particularly true for zoo animals, because they are very diverse and each case has typically attracted minimal empirical investigation. Here, perhaps the best alternative is to use the label 'abnormal repetitive behaviour' (ARB) (cf. Garner, in press-a), a bland term conveying nothing about causation nor even necessarily implying a problem. We will do this in this paper, occasionally using the phrase 'putative stereotypic behaviour' for variation. 'Stereotypic behaviour' is reserved for behaviours demonstrably caused by deficits in captive housing that induce frustration etc. (our suspicion being that future data will show that most ARBs meet this criterion). 
What exactly causes stereotypic behaviours? Mason (in press-a) sums up the state of current knowledge as follows:

'Overall, captive animals perform stereotypic behaviour for the following, non-mutually exclusive, reasons:

(1) internal states induced by the captive environment, and/or cues external to the animal, persistently trigger or motivate a specific behavioural response;

and/or

(2) the environment creates a state of sustained stress which affects how [specific brain regions] elicit and sequence behaviour, resulting in abnormal perseveration; and/or

(3) a past, early rearing environment has affected C.N.S. development, again resulting in abnormal behavioural sequencing, with effects evident long past infancy.

... in some cases this might... be further promoted by endogenous effects such as reinforcing consequences from the behaviours [and increased] predictability may ... emerge through repetition'.

Thus (1)-(3) are the fundamental causes of repetition; while, more speculatively, some stereotypic behaviours may additionally involve 'coping' effects and/or the development of habit-like properties (see also Mason and Latham, 2004). Mason then proposed that forms with 'cause (1)' be called 'frustration-induced stereotypic behaviour', and those with causes (2) and (3), 'malfunction-induced stereotypic behaviour'. Frustration-induced stereotypic behaviours are driven directly by motivational frustration, fear or physical discomfort; are not the product of any underlying dysfunction; and the motor patterns that are repeated reflect the nature of the underlying problem, deriving from attempts to replace a missing normal behaviour, to escape from confinement, or to otherwise alleviate the problem. Malfunction-induced stereotypic behaviours are products of C.N.S. abnormality, co-occur with a suite of other effects (e.g. quantifiable changes in brain physiology/anatomy: Cabib, in press; Lewis et al., in press; and behavioural 'perseveration': see Garner, in press-a, and further discussion below); and the forms of motor pattern repeated may be sometimes be more arbitrary/less naturalistic, not directly reflecting the problem's primary cause (e.g. eye-poking in primates removed from their mothers too early) (reviewed Mason, in press-a).

Leaving aside exact causation as often unknown, to what extent are ARBs displayed by captive wild animals? The best zoos and similar institutions manage their populations with care, but successfully keeping wild species can be challenging, and not infrequently, animals show overgrooming, self-biting, the eating of inedible objects ('pica'), rhythmic rocking or pacing, and other ARBs (e.g. Meyer-Holzapfel, 1968; Templin, 1993; Carlstead, 1998). Accurately quantifying the total global prevalence of such ARBs, i.e. the proportion of the captive population displaying them, is currently impossible: most relevant studies do not sample at random but instead focus on individuals or enclosures where such behaviours are known to be an issue; extrapolating from these would thus over-estimate true prevalence (see e.g., Clubb and Mason, 2007). However, some broader surveys across multiple institutions should reflect the true situation more accurately, at least for a few species. For instance, Mellen et al. (1998, and subsidiary unpublished data) scan-sampled felids across eight zoos. They obtained data from 55 individuals on the presence of stereotypic behaviour, 76\% emerging as affected. Tarou et al. (2005) took an alternative, questionnaire-based approach, analysing returns from 48 AZA-accredited institutions to show that of the 440 individual prosimians living in these zoos, $13.2 \%$ displayed ARBs ranging from pacing to self-harming. More 
recently, Bollen et al. (submitted, cited by Novak and Bollen, in press) similarly surveyed over 3000 zoo primates; they obtained the somewhat lower figure of $7 \%$ for prevalence in prosimians (perhaps reflecting sampling effects and/or their exclusion of self-injurious behaviour from these results), and revealed interesting taxon effects, with prevalences of $7 \%$ in New World monkeys, $13.8 \%$ in Old World monkeys and $39.6 \%$ in apes. Table 1 sums further figures from surveys focussing on particular species or genera. We added census information from the International Species Inventory System (ISIS; www.isis.org) to this table, to estimate what these prevalences suggest are the total numbers of affected animals worldwide. 'Estimate' is the key word here - how accurate or globally representative are these survey figures is unknown, as is the number of zoos not reporting to ISIS (though it is at least equal to the number of reporting zoos - see IUDZG, 1993; WAZA, 2005); and our calculations probably exaggerate the population sizes of large, hard-to-keep species like elephants, while underestimating it for others (e.g. those bear species favoured by Asian bear parks). However, these caveats in mind, two lessons do emerge from Table 1 and the broader surveys above. First, within some taxa, known or putative stereotypic behaviours occur in a considerable proportion of the population. Second, the total number of affected animals is likely over 10000 - this probably being an under-estimate, if the total number of zoo birds and mammals is ca. 600000 (IUDZG, 1993), reflecting that Table 1 covers a just handful of taxa (cf. the ca. 4000 species and sub-species of bird and mammal kept in zoos; Clubb and Mason, 2007).

If 10000 or even tens of thousands of zoo animals perform ARBs, this is a large number of individuals, and yet dwarfed by the tens of millions of stereotypic animals in agricultural systems (Mason and Latham, 2004). Given this context, why should these captive wild animals be of any real interest or concern? This question is the focus of this paper's Section 2. After this, we consider how zoos and breeding centres do and should tackle stereotypic behaviour, comparing 'environmental enrichment' with other approaches (Section 3). Lastly, in Section 4, we focus on enrichment, to discuss how it should be used in practice: e.g. how enrichments should be presented, which subjects should be prioritised, plus what data should be collected to evaluate its success and/or further the fundamental understanding of ARBs.

\section{Why are stereotypic behaviours/ARBs in captive wild animals important?}

ARBs in captive wild animals are important for three reasons. The first is that many indicate environments that cause poor welfare (by which we mean negative affective or emotional states): this raises ethical concerns, and some practical concerns too due to the other likely consequences of stress. The second is that stereotypic behaviours represent a considerable divergence from the behavioural phenotypes of free-living wild animals, and could even indicate C.N.S. dysfunction. This raises further concerns, especially about such animals' direct, intrinsic role in conservation (e.g. their suitability for reintroduction) and even their indirect role (via public education). The third reason is more positive: the diversity of species and rearing/housing conditions represented in zoos is unparalleled, and these institutions thus represent a 'natural experiment' which uniquely allows the generation and test of hypotheses about how captivity affects animals. Thus cases here can give new fundamental insights, which can then be applied to the many species kept in other situations.

\subsection{Stereotypic behaviours/ARBs as a sign of probable poor welfare}

Stereotypic behaviours in captive animals are typically most time-consuming and prevalent in conditions known or believed to be aversive, such as physical confinement and/or low stimulation (e.g. studies of chained/unchained zoo elephants reviewed by Clubb and Mason (2002)); social 
Table 1

The prevalence of abnormal repetitive behaviours in zoos and breeding centers

\begin{tabular}{|c|c|c|c|c|}
\hline Species & $\begin{array}{l}\text { Prevalence expressed } \\
\text { as a } \% \text { (and as a fraction } \\
\text { of the individuals sampled) }\end{array}$ & $\begin{array}{l}\text { Number of } \\
\text { institutions } \\
\text { sampled }\end{array}$ & $\begin{array}{l}\text { Worldwide population: } \\
\text { www.isis.org, November } \\
2005 \text { (estimated worldwide } \\
\text { zoo total, if } 50 \% \text { zoos } \\
\text { report to ISIS; see text) }\end{array}$ & $\begin{array}{l}\text { Estimated } \\
\text { worldwide } \\
\text { number of zoo } \\
\text { animals } \\
\text { affected }\end{array}$ \\
\hline Brown bears (Ursus arctos) & $48 \%(89 / 185)^{\mathrm{a}}$ & 49 & $450(900)$ & 432 \\
\hline Asiatic bears (Ursus thibetanus) & $54 \%(34 / 63)^{\mathrm{a}}$ & 28 & $131(262)$ & 141 \\
\hline $\begin{array}{l}\text { American black bears } \\
\text { (Ursus americanus) }\end{array}$ & $43 \%(6 / 14)^{\mathrm{a}}$ & 7 & $301(601)$ & 258 \\
\hline Sun bears (Helarctos malayanus) & $74 \%(21 / 29)^{\mathrm{a}}$ & 14 & $138(276)$ & 204 \\
\hline Spectacled bears (Tremarctos ornatus) & $60 \%(9 / 15)^{\mathrm{a}}$ & 10 & $140(280)$ & 168 \\
\hline Sloth bears (Melursus ursinus) & $60 \%(9 / 15)^{\mathrm{a}}$ & 7 & $70(140)$ & 84 \\
\hline Polar bears (Ursus maritimus) & $\begin{array}{l}55 \%(68 / 124)^{\mathrm{a}} \\
100 \%(13 / 13)^{\mathrm{b}} \\
82 \%(32 / 39)^{\mathrm{c}} \\
\text { Total assuming each } \\
\text { study surveyed } \\
\text { different animals: } \\
101 / 176=57 \%\end{array}$ & $\begin{array}{l}39 \\
8 \\
18 \\
45\end{array}$ & $199(398)$ & 227 \\
\hline Fennec foxes (Vulpes zerda) & $28 \%(26 / 93)^{\mathrm{d}}$ & 31 & $182(364)$ & 102 \\
\hline $\begin{array}{l}\text { Giraffes and okapi pooled (Giraffa } \\
\text { camelopardalis and Okapia johnstoni) }\end{array}$ & $80 \%(206 / 257)^{\mathrm{e}}$ & 49 & $1285+141=1426(2852)$ & 2282 \\
\hline Gorillas (Gorilla gorilla) & $69 \%(81 / 117)^{\mathrm{f}}$ & 17 & $760(1520)$ & 1049 \\
\hline Black rhinoceroses (Diceros bicornis) & $85 \%(51 / 60)^{\mathrm{g}}$ & 60 & $189(378)$ & 321 \\
\hline $\begin{array}{l}\text { Elephants (Loxodonta Africana and } \\
\text { Elephas maximus pooled) }\end{array}$ & $43 \%(9 / 21)^{\mathrm{h}}$ & 7 & $\begin{array}{l}337+492=829 \\
\left(1658, \text { or } 1167+{ }^{\mathrm{h}} ;\right. \\
\text { smaller number used, } \\
\text { to be conservative })\end{array}$ & 502 \\
\hline Leopards (Panthera pardus) & $100 \%(16 / 16)^{\mathrm{i}}$ & 4 & $629(1258)$ & 1258 \\
\hline Clouded leopards (Neofelis nebulosa) & $49 \%(35 / 72)^{\mathrm{j}}$ & 12 & $185(370)$ & 181 \\
\hline $\begin{array}{l}\text { Lion-tailed macaques } \\
\text { (Macaca silenus) }\end{array}$ & $30 \%(14 / 47)^{\mathrm{k}}$ & 13 & $376(752)$ & 226 \\
\hline
\end{tabular}


Table 1 (Continued)

\begin{tabular}{llll}
\hline Species & $\begin{array}{l}\text { Prevalence expressed } \\
\text { as a \% (and as a fraction } \\
\text { of the individuals sampled) }\end{array}$ & $\begin{array}{l}\text { Number of } \\
\text { institutions } \\
\text { sampled }\end{array}$ & $\begin{array}{l}\text { Worldwide population: } \\
\text { www.isis.org, November } \\
\text { 2005 (estimated worldwide } \\
\text { zoo total, if 50\% zoos } \\
\text { report to ISIS; see text) }\end{array}$ \\
\hline $\begin{array}{l}\text { Lemur (multiple species) } \\
\text { Varecia (multiple species) }\end{array}$ & $6 \%(10 / 172)^{1}$ & $\begin{array}{l}\text { Estimated } \\
\text { worldwide } \\
\text { number of zoo } \\
\text { animals } \\
\text { affected }\end{array}$ \\
Eulemur (multiple species) & $21 \%(34 / 161)^{1}$ & Up to $48^{1}$ & $2054(4108)$ \\
Wombats (Vombatus ursinus) & $17 \%(9 / 53)^{1}$ & Up to $48^{1}$ & $1282(2564)$ \\
Up to $48^{1}$ & $899(1798)$ & 338 \\
\hline
\end{tabular}

a van Keulen-Kromhout (1976): data came from questionnaire surveys to zoos worldwide in the early 1970s; and 'stereotyped behaviour' was defined as 'rhythmical movements'.

b Ames (1993): data were from the UK only, collected by direct observation in the early 1990s; stereotypic behaviour was defined as 'repeated invariant movements which had no apparent function or purpose'.

c Shepherdson et al. (2004): data collected for North American animals only, from keeper reports.

d Carlstead (1991): data collected by questionnaire survey.

e Bashaw et al. (2001): data collected by questionnaire survey.

f Gould and Bres (1986): surveyed zoos for 'regurgitation and reingestion' behaviour by questionnaire, following up with telephone interviews/visits.

g Unpublished information (Carlstead, personal communication) supplemental to Carlstead et al. (1999a,b); keepers were asked to rate their animals on the frequency of 'pacing or stereotypy, i.e. repetitive locomotion in a specific area'.

${ }^{\mathrm{h}}$ Clubb and Mason (2002): searched for studies reporting weaving and other repetitive behaviours in zoo elephants; data here represent totals from four papers pooled. 1167 was the estimated minimum worldwide zoo population in 2001, from a source other than ISIS (Clubb and Mason (2002) citing Koehl 2001).

${ }^{\mathrm{i}}$ Mallapur and Cheelam (2002): data collected by direct observation; relevant behaviours always comprised pacing.

$\mathrm{j}$ Wielebnowski et al. (2002): published prevalence data available for self-plucking and tail-chewing only (not pacing); data collected by keeper questionnaire.

${ }^{k}$ Mallapur et al. (2005): data collected by direct observation; prevalence given here is for pacing only; other ARBs (e.g. self-biting) were also seen, but the overall prevalence of all such behaviours pooled could not be calculated from the data as published.

${ }^{1}$ Tarou et al. (2005): data collected by questionnaire; the zoo sample of 'Up to 48' denotes the total number of zoos replying-this figure was not broken down by genus; stereotypic behaviour includes rhythmic movements like pacing and somersaulting, plus more variable forms such as over-grooming and self-harm.

${ }^{\mathrm{m}}$ Hogan (2004): data collected by questionnaire and sub-sample followed up via direct observation; pacing and gate-pawing were the most common forms. 
isolation (e.g. Foley, 1934; Novak et al., in press-a,-b on primates; Meehan et al., 2003 on parrots); and unavoidable stress or fear (see e.g. Meyer-Holzapfel, 1968; Cabib, in press; Novak et al., in press-b). The pacing of wild captive carnivores illustrates this well: this increases in fennec foxes (Vulpes zerda) with the number of zoo visitors (Carlstead, 1991); in leopard cats (Felis bengalensis) if housed near natural predators and/or without hiding places (Carlstead et al., 1993); in leopards (Panthera pardus) when kept 'off exhibit' in small, barren holding quarters devoid of natural light (Mallapur and Cheelam, 2002); and in many species on 'starve days', i.e. days when not fed (reviewed by Clubb and Vickery, in press). Furthermore, stereotypic behaviours often demonstrably develop from thwarted attempts to perform specific motivated behaviours, suggesting frustration. These include repeated escape attempts in caged laboratory mice (e.g. Nevison et al., 1999a); rooting and pawing in farmed sows unable to nest-build (e.g. Jensen, 1988); and several zoo examples: 'forepaw-hopping' in a polar bear cub, resulting from repeated attempts to reach food that it could smell but not reach (Kolter and Zander, 1995); furplucking in an ocelot, which disappeared when given natural prey to pluck (Hancocks, 1980); pacing in a dingo, which developed from running up and down a trellis separating it from its pack (Meyer-Holzapfel, 1968); and many others where pacing seems to derive from attempts to escape (reviewed Clubb and Vickery, in press). In addition, stereotypic behaviours may co-vary with other signs of stress and disturbance (e.g. the various indices reviewed by Clubb and Mason, 2007; Morgan and Tromborg, 2007; and Tarlow and Blumstein, 2007). One zoo example comes from clouded leopards (Neofelis nebulosa), where pacing correlates with excreted levels of cortisol metabolites, and animals that self-injure (e.g. bite or chew their tails) excrete higher levels than animals which do not (Wielebnowski et al., 2002). Similarly, black rhinoceroses (Diceros bicornis) scoring high in a behavioural factor that includes 'stereotypy', tend to have lower reproductive success (Carlstead et al., 1999a).

These individual accounts paint a picture that was recently confirmed by meta-analysis: Mason and Latham (2004) surveyed publications on ARBs to assess their overall relationship with welfare statistically. A comprehensive collection of several hundred publications was analysed, and accounts scored for reported and/or measured links between these behaviours and other welfare indices. A consistent pattern emerged from those reports in which subjects with different degrees of this behaviour came from different husbandry-types (e.g. contrasting feeding regimens, or differing degrees of environmental enrichment): most linked repetitive behaviours with other signs of poor welfare, and this was significantly different from chance.

Thus environments that induce or increase stereotypic behaviours are likely to decrease welfare. This will seem obvious to many readers, so why emphasise this here? The first reason is that poor welfare is counter to the stated ideals of responsible zoos (e.g. WAZA, 2005). Poor welfare in farm or laboratory animals may generally be accepted by society because viewed as a 'necessary evil' behind cheap food or effective medicines, but it seems much harder to justify in zoos and breeding centres. Indeed it would often conflict with these institutions' practical aims, because poor welfare is likely also to reduce breeding success and increase morbidity/mortality (see e.g. Clubb and Mason, 2007; Morgan and Tromborg, 2007; Tarlow and Blumstein, 2007): important issues, especially for the many captive populations that struggle to be self-sustaining and maintain genetic heterogeneity. Ideally, welfare problems should thus never occur in captive wild animals, and they should never show stereotypic behaviours (cf. the figures in Table 1). The second reason is that zoos sometimes downplay the welfare significance of such behaviours. For instance, in informal conversations with zoo professionals we have heard claims that stereotypic behaviours are of no concern because they allow animals to cope, and beliefs that carnivores' pre-feeding pacing is a harmless version of normal hunting; we have seen the persistent pacing of one female polar bear 
treated as though she was somehow 'difficult' and herself at fault; and we have come across statements that some repetitive behaviours are merely welfare-neutral 'scars' of past housing conditions (following Mason, 1991b), e.g. a sign for the public stating that a particular sloth bear's rocking arose because 'her previous (sic) enclosure [at another zoo] lacked opportunities for stimulating activity' (N. Latham, personal observation). Now, with empirical investigation (see below, and also Mason and Latham, 2004), these ideas might prove at least semi-correct in some cases, but our concern is that zoos sometimes use them simply as 'get out clauses', with no real corroborating evidence (and with obvious, worrying implications for animal welfare). The third reason we emphasise links with welfare is that the Mason and Latham (2004) survey highlights two important caveats when using ARBs to assess zoo animal well-being. One is that the link between husbandry-induced stereotypic behaviour and husbandry-induced stress (etc.) appears probabilistic, not absolute: thus treatments that reduce ARBs are likely to improve welfare, but they do not always do so, and so further measures must be used to judge welfare with certainty (an issue we return to Section 4). The other caveat is that, within a given husbandry-type, the pattern at the individual level differs from that seen when comparing different groups: individuals displaying the most ARB paradoxically fare better than animals responding to the same conditions with relative inactivity (Mason and Latham, 2004, and cf. Section 3). This suggests that these behaviours are better at revealing the poorest environments than they are at identifying the worst off individuals within those environments. As we will see, this has implications for how we should tackle stereotypic behaviours (Section 3) and prioritise individuals for intervention (Section 4).

\subsection{Repetitive/stereotypic behaviour as phenotypically abnormal}

Typically, captive animals' repetitive behaviours are not seen in nature, and often seem the product of activities present in the wild being constrained by enclosure (see e.g. Clubb and Mason, 2007). They thus flag a great divergence between the behavioural phenotypes of captive animals and their free-living counterparts, with the former being abnormal, at least in the statistical sense of 'away from the norm'. Is this important? It probably is if zoos are to have their maximum educational impact: pacing, over-grooming and other disturbing activities are often said to reduce exhibits' educational value, as well their appeal (e.g. Carlstead, 1998; Ironmonger, 1992; Kolter, 1995; Swaisgood and Shepherdson, in press), and recent international zoo mission statements (WAZA, 2005) correspondingly present 'a vision of zoos and aquariums ... maintaining the highest standards of animal welfare ... thus convey[ing] credible conservation education messages to the public'. It is also a problem if we want to use captive individuals to research a species' behaviour in the wild. Such behavioural abnormality arguably matters more, however, if captive wild individuals are actually required to have direct, intrinsic conservation value (i.e. beyond acting as living 'symbols' to inspire interest and concern in the public). For a start, one might question exactly what has been conserved, if natural behaviour patterns are lost and/or replaced with captivity-induced ones; May and Lyles (1987) coined the phrase 'living Latin binomials' for captive individuals that genetically represent particular wild species but behaviourally have little of their phenotype. One might also be concerned about how such animals would fare if reintroduced to the wild, a situation in which captive-bred animals often have low success (e.g. Clark et al., 2002; Frantzen et al., 2001; Griffith et al., 1989; and see Watters and Meehan, 2007).

Whether phenotypic abnormality matters beyond this depends on the fundamental causes of the repetitive behaviour. As mentioned in Section 1, stereotypic behaviour can be 'abnormal' in a second sense: arising from dysfunction or pathology. This would have yet greater implications, if 
true for captive wild animals. Some evidence for this suggestion comes from a growing body of recent behavioural research. Human disorders such as schizophrenia, autism, and some types of brain injury involve forms of C.N.S. dysfunction that impair subjects' proper regulation of behaviour, leading them to produce unnecessary, inappropriate 'uninhibited' responses to external cues. Technically, many of these responses are 'perseverations', namely continuations or reiterations of an activity without the appropriate stimulus being present (e.g. reviewed by Mason and Latham, 2004; Garner, in press-a); and such perseverative tendencies, as quantified in various behavioural tests, correlate with the stereotypic behaviours also performed by these human subjects. Over the last 5 years, in captive animals as diverse as bank voles (Clethrionomys glareolus), orange-winged Amazon parrots (Amazon amazonica), marsh tits (Parus palustris), blue tits (Parus caeruleus), sunbears (Helarctos malayanus), Asiatic black bears (Ursus thibetanus), horses (Equus caballus), and rhesus monkeys (Macaca mulatta) - indeed every species investigated to date - stereotypic behaviours have similarly been found to correlate with perseveration (reviewed by Mason, in press-a). Thus for instance when caged bears are taught an operant response that wins them a food reward, but this is then made unrewarding (by withholding the treat), individuals with the most stereotypic behaviour take the longest to suppress these now-inappropriate responses. This is quite independent of their learning abilities, or their motivations to feed: thus stereotypic bears have no problems acquiring the task, just with abandoning it when it becomes functionless (Vickery and Mason, 2003, 2005).

Such data alone do not demonstrate C.N.S. pathology (they could reflect pre-existing, perfectly normal individual differences in persistence or habit-formation). However, further evidence does suggest that captive wild animals could be dysfunctional. First, it has long been known that when compared with more naturalistic captive conditions, very barren or sociallyimpoverished rearing conditions impair brain development, inducing perseveration and stereotypic behaviours (reviewed Novak et al., in press-a,-b; Lewis et al., in press); while the former, in contrast, can 'protect' animals from later stereotypic behaviour if moved to barren cages (reviewed Lewis et al., in press). However, relatively naturalistic captive conditions still only offer a fraction of the wild's challenges and opportunities, so perhaps even these do not guarantee full normality of function. Consistent with this, captive-born wild animals often display more ARB than wild-born counterparts caught and caged as adults (Mason, in press-b; Latham and Mason, 2006). Second, C.N.S. pathology would help explain some odd traits observed in stereotypic captive wild animals: self-damage, as in the self-biting of clouded leopards (Wielebnowski et al., 2002) and zoo primates (Bollen et al., submitted, cited by Novak and Bollen, in press) or the pacing that sometimes persists despite causing abrasions or sores (Morris, 1964; Meyer-Holzapfel, 1968; reviewed Mason, 1991a); stereotypic behaviours that appear resistant to environmental enrichment (reviewed Mason and Latham, 2004); and finally, the way some ARBs seem to interfere with normal social or parental interactions (Carlstead and Shepherdson, 1994): e.g. males pacing or pirouetting rather than courting receptive females (Freeman, 1983; Swaisgood, personal communication), and females pacing instead of caring for their infants (Widholzer and Voss, 1978; Swaisgood, personal communication; Mason, personal observation).

The evidence that stereotypic zoo animals may be dysfunctional is currently indirect, and future work is needed to assess whether this really is an issue. But why is it important to recognise this as a possibility? First, because - perhaps over-optimistically - it is currently often given little consideration (e.g. Swaisgood and Shepherdson, in press). Second, such changes could arise from severe stress (Cabib, in press), and thence indicate severe welfare problems, in the past at least, that should have been avoided. Third, C.N.S. dysfunction would further 
diminish such animals' direct conservation value, e.g. by potentially interfering with breeding (as suggested above) or reducing the chances of reintroduction success (e.g. Vickery and Mason, 2003, 2005). Fourth and finally, such effects would have implications for how environmental enrichments should be presented, and how their success should be evaluated (see Section 4).

\subsection{Zoo and breeding centres as resources for understanding the effects of captivity}

The sections above present negative reasons why zoos and breeding centres should be interested in ARBs. Here we add some positive ones. As mentioned in Section 1, most stereotypic animals occur in agricultural systems; indeed in some types of farm (e.g. sow breeding units), nearly all animals are stereotypic at certain stages of production, and this, combined with the huge scale on which food animals are kept, makes for a global total of many tens of millions of affected individuals (Mason and Latham, 2004). Laboratory animals probably represent the next most stereotypic group: the many millions of mice kept for research ensure that worldwide, their stereotypic behaviours are numerous, while again, in some set-ups (e.g. single-housed primates), the vast majority of individuals are affected (e.g. Novak et al., in press-a,-b). There is also growing concern about the millions of companion animals, some of which (e.g. lone-housed, concentrated-fed horses; some breeds of dogs, especially if stressed or socially isolated) are prone to such behaviours (Mills and Luescher, in press). Now, research on the behaviour of zoo animals can be difficult (e.g. Clubb and Vickery, in press; Swaisgood and Shepherdson, 2005, in press), but it does bring with it some unique advantages due the great variation in housing, rearing and species-type across such institutions. This potentially means that research into the stereotypic behaviours of zoo animals may have useful wider implications for these other systems and species that cause rather more concern.

To illustrate, the variance between enclosures allows multi-zoo studies to statistically identify aspects of husbandry associated with stereotypic behaviour (e.g. Mellen, 1991; Mellen et al., 1998; Bashaw et al., 2001; Carlstead et al., 1999b; Wielebnowski et al., 2002), often pin-pointing variables that could well be important in other systems too (e.g. lack of opportunities to hide/ retreat; excess noise levels; and poor quality contact with human carers). The effects of rearing histories, e.g. whether mother-reared or hand-reared by humans, can also be empirically assessed (see e.g., Forthman and Bakeman, 1992; Marriner and Drickamer, 1994), since varying far more for zoo animals than for, say, laboratory or farm animal populations. Above, we thus mentioned intriguing differences emerging between wild-caught and captive-bred animals, and although most of this evidence came from wild animals caught and bred for laboratory research, some did come from zoos (Mason, in press-b; Latham and Mason, 2006), and it is future zoo research, capitalising on the myriad species these institutions hold, that will confirm or modify this picture. The myriad species, and more importantly their diverse ecological niches and varying responses to captivity, can also give unique insights into the biological risk factors for stereotypic behaviours by allowing the use of 'comparative methods' to test hypotheses it would be near impossible to tackle experimentally (see Clubb and Mason, 2003, 2007, on the origins of carnivore pacing). Since similar variance in natural ecological niche and degree of ARB occurs in primates (e.g. Novak and Bollen, in press) and other taxa (e.g. see Clubb and Mason, 2004), this approach could yield insights in the future that help explain why rodents, primates and ungulates respond to farm and laboratory conditions in the ways that they do. Zoos have also enabled the test of an old idea-that taxa differ in their responses to captivity, with carnivores being more prone to pacing. We surveyed reports of repetitive behaviour across the four main captive mammalian orders (according to Magin et al., 1994). (This work is now some years old, but 
shown here because to date only presented in non-peer reviewed contributions). Reports primarily came from the papers reviewed by Mason (1991a); the International Society for Applied Ethology's congress proceedings 1991-2000; all International Zoo Yearbooks (19592000); and all volumes of Zoo Biology (1982-2000), yielding observations from a total of 121 species. Analyses revealed that stereotypic Carnivora do indeed systematically favour locomotory movements, while ungulates, and, to a lesser extent primates, display oral forms (see Fig. 1). Since husbandry differences were controlled for as far as possible (see figure caption), this suggests the fundamental importance of natural species biology in determining responses to captivity: a finding only possible through zoo data.

Finally, data from zoos concerning the effects of environmental enrichment are also potentially very useful. Good zoos often devote much effort to alleviating undesired behaviours via occupational therapy, altered feeding regimes, and providing larger or more complex enclosures (e.g. Markowitz et al., 1978; Shepherdson et al., 1998; Swaisgood and Shepherdson, in press). The most immediate value of such studies is to reveal the relative effectiveness of different approaches, on a species by species basis (and we support recent pleas that zoos do more to collect such information consistently and publicise both failures and successes: Swaisgood and Shepherdson, 2005, in press; Barber and Shepherdson, in press). However, meta-analyses of such studies yield interesting findings with potentially broad applicability. For instance, Swaisgood

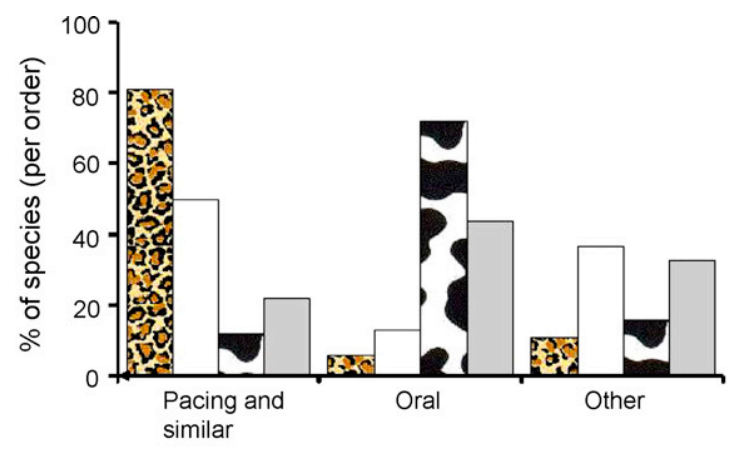

Sole/most common form of abnormal repetitive behaviour

Key:

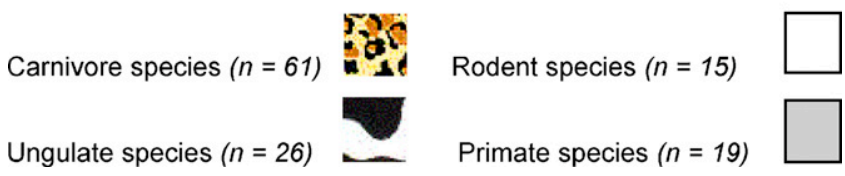

Fig. 1. The taxonomic distribution of different forms of abnormal repetitive behaviour. ARBs in affected captive animals across 121 species were categorised as: (1) pacing and similar, i.e. locomotory movements; (2) oral, e.g. sham-chewing; (3) other: non-locomotory body movements, e.g. body-rocking, repetitive jumping. Juveniles were excluded, to rule out repetitive behaviours relating to play, as were animals with severe C.N.S. dysfunction (e.g. subjects experimentally lesioned, treated with psychoactive substances, or performing self-injurious behaviours-in practice largely laboratory rodents and primates). The following were also excluded, to minimise effects of husbandry differences between taxa: food-deprived animals (largely farmed pigs); animals exposed experimentally to intermittent schedules of reinforcement' (largely laboratory rodents); and animals very prematurely separated from their mothers (largely dairy cattle and laboratory primates). Restraint (largely applying to horses, cattle and horses) was controlled for by scoring swaying/ weaving as 'Pacing' in tethered subjects. Each species was catagorised according to its sole or commonest form (according to time budget data, or in the absence of this, the number of times each form was reported). The occurrence of different ARB categories varied significantly varied with taxon $\left(\chi^{2}=51.17\right.$, d.f. $\left.=6, p<0.001\right)$. 
and Shepherdson (in press) found suggestions that enrichments that were in place for longer (months rather than weeks) reduce stereotypic behaviours to the greatest extent. Furthermore, both these authors (Swaisgood and Shepherdson, 2005, in press) and another (Shyne, in press) found that in cross-study comparisons, different types of enrichment (e.g. foraging-based forms, increased environmental complexity, etc.) did not appear to vary in their efficacy. This last finding raises two new hypotheses for future test, one logistic - that in practice, different enrichments are being differentially selected and targeted to particular cases - and one biological: that even on a case by case basis, wild animals' stereotypic behaviours are equally ameliorated by a diverse range of environmental improvements, an idea we discuss further below.

Mason and Latham (2004) and Mason (in press-a) made specific predictions that could be tested in zoo-based enrichment studies, proposing that the specificity, time-course and magnitude of enrichment effects could help the fundamental understanding of ARBs. We introduce two such ideas here, to be expanded on in Section 4. First, they hypothesised that frustration-induced stereotypic behaviours (see Section 1) would only be ameliorated by specific changes in housing that rectify this underlying frustration. When these are presented, the stereotypic behaviours should be reduced rapidly, i.e. as soon as the enrichment is utilised (one possible example is a pacing armadillo which, when given an earth floor, immediately stopped pacing and dug a hole in which it slept; its pacing only resumed when the earth was removed: Meyer-Holzapfel, 1968). Dysfunction-induced stereotypic behaviours, in contrast, they hypothesised to be generally slow and difficult to reduce (the best-documented examples coming from deprivation-reared primates: see Novak et al., in press-a); and furthermore, enrichments may initially stress the affected animals (see Section 4). These stereotypic behaviours may also have less specificity in terms of enrichment, being potentially reversible by any factor that helps counteract the underlying deficit (e.g. any change that reduces stress), even if not reversing the original cause of the problem (e.g. see Novak et al., in press-c, for the diverse treatments that can successfully reduce some primate stereotypic behaviours; and Mills and Luescher, in press for a similar overview of 'behavioural problems' in companion animals). This is why we found the possible effect of treatment longevity, and the apparent lack of specificity, in the two cited meta-analyses so intriguing (although the last effect could also be explained in other ways, e.g. diverse enrichments may all reduce ARBs simply by using up animals' time: see below). Enrichment studies in zoos could thus help test fundamental ideas, a topic returned to in Section 4.

\section{Why should stereotypic behaviours/ARBs be tackled using environmental enrichments?}

In practice, ARBs may sometimes be ignored or 'explained away' (see Section 2.1), but this is clearly not adequate in any institution truly concerned with public education or animal care. Occasionally, a stereotypic animal may instead be taken off exhibit (e.g. by transferred to another zoo; e.g. S. Vickery, personal observation) but again this is hardly a solution at the level of the animal. However, very often, real attempts are made to reduce or prevent ARBs, taking five broad forms: genetic selection (to start with the least used); the use of pharmacological compounds; the positive reinforcement of alternative behaviours; physical prevention or punishment; and, most commonly, environmental enrichment. Below, we discuss the pros and cons of each. First, however, we give some relevant context by reviewing in more detail something alluded to above: that within a population of similarly housed animals, ARBs can have positive correlates. Mason and Latham (2004) analysed 90 reports in which stereotypic individuals were compared with peers showing little or no ARB despite similar husbandry. They found that according to other 
welfare measures, the former seemed to fare better than the latter. Now, the idea that ARBs may help animals to cope with sub-optimal environments is not new (reviewed Würbel et al., in press; Mason, in press-a), and is one possible explanation. 'Coping' effects could arise because novel behaviour patterns developed in captivity generate some or all of the sensory/physiological feedback provided by full natural behaviour patterns (a principal central to much enrichmentuse); or it could arise in a manner suggested from studies of humans, for whom some rhythmic behaviours patterns are inherently calming (Mason and Latham, 2004). Instead, however, a second possible explanation for this pattern is that in sub-optimal environments, those individuals with little ARB fail to develop it for reasons detrimental to welfare, e.g. they are so fearful that they hide all day, so arthritic that they show little movement of any kind, or impaired in some other manner (Mason, in press-a). Whatever is happening - and this is an important topic for future research - this picture adds important subtleties to the 'take-home message' of Section 2.1, and has implications for the appropriateness of different ways of reducing ARB.

The first potential method, genetic selection, has occasionally been used in some systems to reduce putative stereotypic behaviours within a population. Thus experimentally, stereotypic behaviour was successfully selected against in poultry (Mills et al., 1985a,b); while on a practical level, it is now national policy in the Netherlands for mink ranchers to breed this behaviour out of their farmed populations (e.g. EC, 2001; Vinke et al., 2002). Zoos may occasionally indirectly do similar, being said to sometimes not replace or breed from highly stereotypic individuals (e.g. Ironmonger, 1992; Irven, 1993; Dollinger et al., 1996). However, this approach is in its infancy in applied ethology, and not currently of major relevance to zoos. So, should it be encouraged as a future strategy? Breeding for animals which are not frustrated by captive conditions, or not vulnerable to the stresses inherent in some early rearing practices, could certainly be an effective way of improving welfare. Mills' work provides a nice case: here, the reduction in hens' pacing was achieved by selecting against the underlying motivation (to search for a nest), and so was very likely to enhance welfare. When zoo animals have but indirect conservation value, we could thus see this as being a valuable tool. There are two caveats, however; the first is that where captive wild animals are to have direct, intrinsic conservation value (e.g. are to be released back into the wild), this clearly is not appropriate; and the second is that selecting against ARB itself rather than its underlying causes brings with it a danger of selecting for inactive phenotypes that, as we have cautioned, may have still poorer welfare (the Dutch mink providing a troubling example: here, stereotypic phenotypes are selected against once evident on a farm, despite often being linked with lower endocrine stress responses; reviewed in EC, 2001; Mason and Latham, 2004).

The second approach to ARB reduction is the use of pharmacological agents such as serotonin-reuptake inhibitors (fluoxetine or 'Prozac' being a well-known example). This approach is quite widely used in the 'companion animal' world, inspiring some similar interventions in zoos. Drugs it is hoped have anti-psychotic or anti-depressant effects have thus been used with captive wild bears and primates (Poulsen et al., 1996, 1998; Uchida et al., 1998; Tarou et al., 2005), and homeopathic remedies even tried in one instance (Jordon-Owers, 2003). Some have successfully reduced stereotypic behaviour. For example, the use of oral serotoninreuptake inhibitors seemed very successful in a polar bear who had been pacing for two decades, 'huffing' (a repetitive vocalization, accompanied by a facial tic), and possibly also fur-plucking: the drug abolished her pacing, improved her coat quality, and even increased her apparent alertness and degree of normal behaviour (Poulsen et al., 1996, 1998). Previous tactics, e.g. enriched-based ones, had failed to achieve this. However, while fluoxetine reduced this animal's ARBs, a similar course of treatment had some exacerbating effects on the pacing of her similarly aged companion (Poulsen et al., 1998): an effect neither predicted nor understood. These authors 
therefore do not regard this approach as a magic bullet, and are careful to emphasise that it is not for use without real improvements in enclosure design and husbandry (Poulsen and Teskey, in press). After all, long-term pharmacological intervention seems a rather perverse solution to problems fundamentally caused by housing (and would also conflict with animals' direct conservation value). There are also concerns about the dearth of real knowledge on how such drugs act; even for companion animals, there have been negligible proper clinical trials (Mills and Luescher, in press). Thus there is a lack of knowledge about contraindications (which may include some sub-types of ARB; Garner, in press-b), best dosing regimes, and side-effects (including ones that could even mask the symptoms of ARB, e.g. by causing nausea or lethargy; Garner, in press-b; Mills and Luescher, in press). Therefore overall, although short-term pharmacological interventions can doubtless truly help in the companion animal world (when part of a holistic treatment strategy supervised by a careful, knowledgeable practitioner: see Mills and Luescher, in press for an excellent account), we would caution against their current use in zoo animals.

A third way to tackle ARBs is to actively reinforce non-stereotypic behaviours with reward, as used successfully in some companion animal cases (see Mills and Luescher, in press), many human cases (e.g. Shabani et al., 2001; and reviewed by Bloomsmith et al., 2007), and some zoo cases. For example, this technique was part of a successful intervention to improve a captive dolphin's welfare and reduce his repetitive regurgitation (Laule, 1993): here, extra time was spent with the subject immediately following a feed, during which he was rewarded with attention and play for not regurgitating. Bloomsmith et al. (2007) give further examples. This tactic would generally seem a benign approach, and perhaps could be an adjunct to help encourage enrichment-use (see below). However, it may not tackle the underlying causes of ARB (but see Bloomsmith et al., 2007) and is also very labour-intensive. Other possible disadvantages could include adventitiously conditioning other behaviour patterns into becoming repetitive, or putting an animal in a state of conflict (as motivations to perform an ARB compete with those to perform the human-rewarded ones). Perhaps one of these latter effects could explain why when Hare (1995) used remote-controlled feeders to reinforce only 'desirable' behaviours (e.g. active investigative behaviours) in two brown bears (Ursus arctos), there was an overall reduction in stereotypic behaviour but one animal seemed to develop schedule-induced polydipsia (excessive drinking).

The successful intervention to reduce a dolphin's repetitive regurgitation also used mild punishment (e.g. verbal reprimands, 'time out'); and in fact punishment or physical prevention is probably one of the commonest responses to undesired behaviours. Thus attempts to reduce ARB in bears include obstructing pacing routes (Hennessy, 1996), similar also being tried for an armadillo (Meyer-Holzapfel, 1968). Tarou et al. (2003) likewise describe an attempt to deter stereotypic licking in giraffes by spraying enclosure walls with bitter chemicals. In terms of unpublished occurrences, we have also seen the removal of a branch used for repetitive somersaulting, in the case of a kinkajou (G. Mason, personal observation); the punishment of an elephant for swaying during keeper interactions (R. Clubb, personal observation); the emptying of a pool to prevent stereotypic swimming by a polar bear (G. Mason, personal observation); and the roughening of an area of concrete paced upon by another polar bear, to make her movements there uncomfortable (S. Vickery, personal observation). Zoos are not alone in this approach: it is commonly used with horses, where a variety of unpleasant-tasting pastes, restrictive collars and even surgery may be used to stop animals 'crib-biting' (see review by Ödberg, in press); and it has even been advocated in the pet world, where bitter-tasting topical substances may be used to stop rodents over-grooming (e.g. Haines and Hanes, 2004). However, the effectiveness of such methods is uncertain, since animals often seem to simply shift their ARB to a different location, 
incorporate an imposed obstacle into the behaviour (Meyer-Holzapfel, 1968; Vickery, 2003; Tarou et al., 2003), or even increase their ARB due to the resulting stress (see Bloomsmith et al., 2007). This approach thus also brings with it welfare concerns: many warn of the potential dangers of simply blocking a putative stereotypic behaviour (e.g. Schofield and Mulville, 1998; Mason and Latham, 2004; Ödberg, in press), especially given the risk that such approaches may prevent behaviours animals find stress-relieving or otherwise beneficial (see above). Finally, this approach clearly does not tackle the underlying causes of ARB, unlike our final method: environmental enrichment.

Environmental enrichment is the probably the most common means of tackling ARBs. It has been extensively reviewed elsewhere, and will be very familiar to readers. Enrichment is usually thought of in terms of changes to the structure and content of enclosures, although other changes in husbandry (e.g. reductions in visitor noise, changes in keeper-animal interactions) can also sometimes be subsumed under this label. Good enrichments are thought to offer animals opportunities to perform activities that they prefer over stereotypic behaviours, reduce the motivations driving ARBs, and/or offer enhanced control (including opportunities to hide/ retreat) (e.g. Swaisgood and Shepherdson, in press). They may thus reduce ARBs by reducing underlying frustrations, reducing contributory stress levels, and/or simply by taking up time with preferred behaviours (which then reduces the time-budget devoted to ARBs, rather like the differential reinforcement of alternatives discussed above) - although in practice, how a successful enrichment acts is typically unknown (see Swaisgood and Shepherdson, in press). Enrichments' benefits are obvious: done well, they tackle the roots of the problem; and even where they do not, still probably improve welfare by offering animals preferred new behavioural opportunities. Naturalistic enrichments may even enhance animals' direct conservation value. Furthermore, they give animals a choice as to whether or not to participate in the treatment (unlike physical prevention, or pharmacological approaches).

The few potential down-sides are that non-naturalistic enrichments, or practices involving rewarding keeper contact, are not appropriate for that minority of individuals with direct, intrinsic conservation value (although valuable to the rest); some animals may potentially find novelty, or unpredictability, frightening or stressful (or enrichments may cause resource-defence aggression: Nevison et al., 1999b; Young, 2003); and some increases in enclosure complexity could merely block ARBs or make them more complex in appearance (cf. e.g. Bergeron et al., in press on oral behaviours in hungry animals). Furthermore, husbandry changes that decrease the predictability of food arrival may well diminish pre-feeding ARBs and yet also diminish welfare (cf. e.g. Bassett and Buchanan-Smith, 2007). Finally, the last down-side is that enrichments never seem to 'work' $100 \%$. Thus only about $50 \%$ of attempts succeed in reducing ARBs (Swaisgood and Shepherdson, 2005), and they effect a mean reduction of just 50\% (Swaisgood and Shepherdson, in press). Thus no study has managed to abolish ARBs in all its subjects (Swaisgood and Shepherdson, in press; Shyne, in press) - suggesting either that the enrichments being used are never quite optimal, or that by the time they are tackled, ARBs have become resistant to change.

\section{How to present and evaluate environmental enrichments}

Many previous authors have reviewed how to select, implement and evaluate the success of enrichments in the zoo world (e.g. Shepherdson et al., 1998; Barber and Shepherdson, in press; Swaisgood and Shepherdson, in press). Rather than duplicate this, we focus here on new ideas suggested by recent findings and hypotheses re. stereotypic behaviour. 


\subsection{Choice of subject}

If the aim is simply to reduce unfavourable comments from the public, then the choice is simple: prioritise animals with the most conspicuous, unaesthetic ARB. However, aims are often - implicitly at least - more animal-centred than that, typically focussing on welfare. Young (2003) therefore makes the rational suggestion that we should prioritise species most likely to be consciously sentient. The truth is, however, that we do not know which these are, although our instinctive empathy for mammals and birds typically leads enrichments - rightly or wrongly - to be targeted at these rather than poikilotherms. At the species level, it would also be efficient to pro-actively target taxa known to be at risk, before they display problems, to try and pre-empt their emergence: e.g. apes over prosimians (see Section 2), and wide-ranging over 'stay-at-home' carnivores (see Clubb and Mason, 2007). It also would be fair to target non-endangered species to a greater extent: endangered species currently attract c. $50 \%$ of all enrichment attempts, despite making up only about $15 \%$ of zoo animals (Swaisgood and Shepherdson, 2005).

Moving away from species-level decisions, and returning the focus to welfare, zoos should obviously target those individuals or groups most likely to be experiencing poor welfare in their current housing conditions. But how to do this? Poor welfare should not be assessed by means of ARB alone. As we have seen, ARBs do help identify welfare-poor conditions. Nevertheless, as we also saw above, those individuals with little or no ARB in such sub-optimal conditions may be faring most poorly, and they must not be over-looked. Furthermore, these survey data also show many exceptions to this pattern - presumably reflecting that some animals with no ARB are welladapted to their captive environments; and that some ARBs have no beneficial correlates. This complexity emphasises how important it is identify the neediest subjects using multiple welfare measures (see previous references above). However, if lack of expertise or resources makes this impossible, then in practice some helpful guiding questions might be: (a) Are there a priori reasons for thinking some individuals may be most at risk (e.g. wild-caught animals which might be most frustrated by confinement or most scared of humans; or severely maternally-deprived animals which might be very poor at coping with stressors)?; (b) Do those individuals with no/low ARB appear active, alert and exploratory; or instead, are they inactive/more prone to hide than their stereotypic conspecifics (in which case we should probably be particularly concerned for their welfare)?; (c) What does an ARB look like? If flexible, variable and somewhat erratic (cf. e.g. the 'restless' behaviour of young mink and some caged pandas; Mason, 1993; Owen et al., 2005), it is probably at an early stage of development, which could mean that it is a reliable indicator of current, on-going frustration (Mason and Latham, 2004), and also relatively 'curable' (Mason, in press-a).

\subsection{Presenting the enrichment}

The choice of enrichment will often be shaped by previous reported successes (see e.g. Barber and Shepherdson, in press, and various on-line enrichment databases), and also inferred from the nature of the ARB, including timing and location (e.g. oral forms, especially displayed around feeding, may indicate that foraging enrichments are called for; see e.g. Bergeron et al., in press). To this we would add two suggestions. First, be imaginative and think about the functions of the animal's behaviour patterns in the wild. For instance, Wiedenmeyer, in his study of stereotypic digging in caged gerbils, did not leap to the assumption that these animals need a digging substrate. He did try this as an enrichment (in the form of sand), but he also reasoned that in the wild, these animals dig until they have attained a suitably tunnel-like burrow. He therefore offered tunnel-like dens as enrichments too, and found that these were far more effective than 
sand in preventing the digging ARB from developing (e.g. Wiedenmayer, 1997). Second, be aware that in terms of appearance, some ARBs will, unfortunately, give little clue as to their underlying causation. To give just one example (Mason, in press-a gives others), walruses are prone to stereotypic rooting which can cause severe tusk wear, suggesting that for these animals, which naturally would spend a large part of their day digging for bottom-dwelling invertebrates, rooting troughs would be a valuable enrichment. However, interestingly, such enrichments successfully tackle a form of stereotypic behaviour quite unrelated to such foraging: repeated swimming in circles (Kastelein and Wiepkema, 1989) - perhaps because environmental deficiencies give rise to repeated search or escape attempts (cf. e.g. Mason, in press-a; Clubb and Vickery, in press).

If there is cause to think that the animal may be dysfunctional, we also suggest both gentleness and patience when using enrichments. To illustrate, isolation-reared primates are very prone to abnormal behaviour (see Novak et al., in press-a,-b), and this behaviour is hard - although not impossible - to reduce. The most successful intervention involved pairing the isolates with younger monkeys. Prior to this, the isolates spent nearly half their time self-clasping, rocking and huddling, but eventually, after 18 weeks of treatment, this value fell to under $10 \%$ (reviewed by Novak et al., in press-a,-b). Such lengthy treatment periods may be needed because underlying C.N.S. changes are hard to reverse, and/or because these subjects need time to find the enrichments enriching; after all, in humans with clinical behavioural conditions, perseveration and its accompanying stereotypic behaviour can be linked with reduced abilities to respond appropriately to novel stimuli and tendencies to find environmental change stressful (e.g. Turner, 1999a,b; NAS, 2002; see also Rowe et al., 1998 on responses to novelty in cognitively impaired rats).

Finally, we suggest that zoos look to the companion animal literature for ideas as to how to improve the effectiveness of enrichment. Mills and Luescher (in press) describe several cases where - unlike the typical response in zoo animals - ARBs in companion animals were successfully abolished. Leaving aside the difficult issue of drug-use (see above), one lesson that perhaps could be applied from this field is looking for all possible sources of stress in the subject's life, including inconsistent human-animal interactions and difficult relationships between animals housed together. Another is the positive reinforcement of alternative behaviours as a useful adjunct. The approaches these authors advocate are typically more labour-intensive (and holistic) than the usual zoo enrichment regime, but their success suggests that such investment could be worth it.

\subsection{Evaluating the success of enrichment}

If an enrichment's goal is solely to reduce or eliminate ARB, then one that does not do this has self-evidently failed. Such cases have long been reported (e.g. the persistence of pacing even after animals are transferred from small, barren enclosures to large, enriched ones; Meyer-Holzapfel, 1968), and look to comprise around half of enrichment attempts in zoos (see references above). But if the aim is to improve welfare, then what to conclude in such instances?

This is more complex, and we suggest two possibilities that can only be teased apart with additional data. The first is that the problems underlying the ARB have indeed been resolved, but the ARB itself has been left untouched. This is essentially the 'scar' idea introduced in Section 2, and two principle mechanisms have been suggested to underlie it (see below). This as an important possibility (see also Mason, 1991b; Mason and Latham, 2004). For example, Eaton et al. (1994) found that housing isolation-reared rhesus macaques in pairs did not reduce ARB, 
and so concluded that pair-housing did not improve welfare. We would contend this to be a dangerous conclusion to reach without further data, since the monkeys' welfare could have been improved but their underlying perseverative dysfunctions simply left untouched. Ames (1994) similarly advised for bears that enrichments should be persevered with, even when they seem to have little impact on behaviour, because stereotypic behaviours can persist long after their initial causes have successfully been dealt with. On the other hand, however, zoos should never assume that such effects are the explanation without good evidence, especially as even ARBs many years old can diminish rapidly with the right enrichments (see e.g. Cooper et al., 2000 on horses). This is important, because the alternative explanation for stubborn ARBs is that the enrichment has failed to tackle the welfare problem underlying it. To illustrate, someone trying to tackle spotpecking in canaries by increasing cage size or complexity would probably find no impact at all on this ARB (see Keiper, 1969, 1970, 1975). It might then be tempting to dismiss spot-pecking is a mere scar of past conditions. However, the true explanation would be that the wrong enrichments had been provided: that for spot-pecking to stop, other stimuli are needed, e.g. more complex foraging opportunities (Keiper, 1969, 1970, 1975). Recognising this second possibility is thus important if continuing welfare problems are not to be overlooked. Ways of teasing apart these two explanations include looking at some of the properties of the ARB (see Sections 4.1 and 4.4); trying multiple enrichments to see if one succeeds where others fail; and assessing subjects' welfare to see how they compare with conspecifics in conditions so naturalistic that ARBs are never seen.

We have already referenced reviews in this volume pointing to useful measures of welfare state, and taking such additional measures would not just be useful in the problem outlined above. Such additional data would also help ensure that when enrichments do reduce ARBs, they really do so by improving welfare-alternative explanations being that they merely make ARBs more aesthetic in appearance, or even that they impede it or render the cues eliciting it less predictable: two scenarios that would likely diminish welfare (see above). These additional data would also help us interpret those rare but puzzling instances where the enrichment-use is itself stereotyped in appearance (e.g. wheel-running; see Latham and Würbel, in press), or where enrichment-use actually increases stereotypic behaviour (e.g. caged mink given balls to play with show enhanced levels of pacing ([Jeppesen and Falkenberg, 1990]; while farmed pigs given roughage to chew, or more frequent rather than less frequent meals, can show increased levels of oral ARBs [Broom and Potter 1984; Douglas et al., 1998]). In all these instances, another useful approach would also be to assess animals' strength of preference for the presented enrichments, since if the animal strongly prefers them, its welfare is indeed likely to be improved by them (e.g. Dawkins, 1990; Mason et al., 2001). This can be done by quantifying the effort animals are prepared to make to utilise it, e.g. as assessed via working for access (and N.B. this is not the same as the time spent using it: 'usage' time-budgets and strengths of preference are quite independent: Mason et al., 2002). In addition, collecting further welfare-relevant data could also help us understand the aetiologies of stereotypic behaviour patterns more fully, as we discuss next.

\subsection{Data to help us understand stereotypic behaviour}

Currently, enrichments influence ARBs very differently from one case to the next. To understand why, we need to assess how different enrichments affect animals (e.g. the degree to which they are used, to assess time budget effects; the degree to which they are preferred, to quantify their value to animals; and the degree to which they affect measured stress), but data on such variables are also rarely collected. We also need more information on ARBs themselves, 
to investigate whether some have properties conferring resistance to enrichment. However, again, this typically does not happen: few measure ARBs attributes beyond mere time budgets. Thus currently, when we see intriguing findings like oral ARBs being more effectively reduced by enrichment than other forms of ARB (Swaisgood and Shepherdson, 2005), we cannot say whether this is because oral ARBs are somehow inherently more treatable; whether the ungulates who favour these forms (see Fig. 1) are somehow inherently more treatable; or whether these forms are being tackled with particularly appropriate enrichments.

So, what might affect the ease with which an ARB is reduced by enrichment? Above, we hypothesised that frustration-induced ARBs will require very specific enrichments, if they are to be reduced by means other than mere time-budget effects. Thus across diverse enrichments, we should see effects ranging from abolition through to zero impact (if time-budgets are controlled for), with graded responses reflecting a reduction but not elimination of the underlying frustration. The most strongly preferred treatments should be most effective in tackling the ARB, and best improve welfare as assessed via other measures; measured welfare should also improve exactly as ARB falls (Mason and Latham, 2004). We also predict that any effects would be rapid, since once enrichment-use has commenced, then if it tackles frustration, it should have an immediate effect on the ARB.

On top of this, if some frustration-induced ARBs have beneficial feedback akin to that provided by natural behaviour patterns (see above), then animals should not only require very specific enrichments, but also very good quality ones if they are to be effective. This is because the enrichment not only needs to tackle the underlying motivation: it needs to tackle it more effectively than the animal's own ARB, so that the individual prefers to use the human-provided enrichment rather than continue with its own self-made version. Such coping ARBs should also have an additional property: the time since a bout of ARB should predict an animal's use of an enrichment. This is because if performing the ARB does indeed reduce the underlying frustration, this should be evidenced in a reduced immediate motivation to use a relevant enrichment (cf. Lindberg and Nicol, 1997 and Olsson et al., 2002 on 'sham dust-bathing' in hens).

The other hypothesised form of coping is that certain rhythmic behaviours are calming (cf. 'mantra effects' in humans; Mason and Latham, 2004). We tentatively suggest that any such ARBs should also have certain characteristics in terms of enrichment-use. First, because such ARBs may be utilised to reduce stress, they may be reduced by any enrichment that reduces acute or chronic stress. We would thus expect them to show less specificity than the types of ARB above; but similarly to be reduced rapidly, i.e. as soon as stress is reduced (Mason and Latham, 2004). Second, if enrichments allow rhythmic actions (e.g. swinging, rocking, perhaps even wheel-running), they might offer acceptable alternatives to the spontaneous ARB (while not actually reducing the underlying causes of the behaviour). Third, animals with such behaviours may be unresponsive to external stimuli while engaged in a bout, but normally alert and attentive while not; thus an enrichment added as a high-incentive 'probe' between bouts should attract attention (even if the animal does not break off from its current behaviour), but an enrichment added during a bout may be quite unnoticed.

A variant of this last prediction applies to two final mechanisms that are 'scars of the past': dysfunction and habit. That ARBs may become habit-like through repetition has long been speculated (see Section 2; Mason and Latham, 2004; Mason, in press-a). For instance, this was invoked to explain why an animal might find it difficult to alter its ARB, bumping into obstacles placed in its path (see Fentress, 1973, 1976); why some caged hens continue sham dust-bathing, despite being given litter (Olsson et al., 2002); and why with age, stereotypic behaviour in voles 
become harder to alleviate with enrichment (e.g. Cooper et al., 1996). However, deprivation- or stress-induced dysfunction and perseveration (see above) could equally explain such observations. So how to tease apart these last two hypotheses? This is difficult without good developmental studies: the habit-learning idea predicts that the ARB alone becomes routine-like with repetition, with no other changes in the animal's behaviour, while the dysfunction idea predicts a generalised suite of behavioural changes over time, affected animals becoming behaviourally abnormal (e.g. perseverative) even when not stereotyping. However, certain responses to external disturbances, including enrichments, could help reveal mechanism. If a novel stimulus occurs during an ARB, animals with both dysfunctional and habitual ARBs may continue the bout, but, unlike the 'mantra-like' ARBs above, may show signs of attention (e.g. via gaze direction). If they then break off, however, a habit-like sequence should require re-starting from a particular point, as observed in some musicians (Mechner, 1995), geese egg-rolling with their bills (Tinbergen, 1951), and rats in a maze which, if disturbed half way down a run, return to the 'start box' before repeating their choice (Lashley, 1921). Actions similar to a component of a habit-like ARB may also trigger the rest of the sequence; as Norman (1981) put it, 'pass too near a well-formed habit and it will capture your behaviour'. This could perhaps explain why some enrichment-use paradoxically increases ARBs (see above). Furthermore, if the enrichment reduces the ARB (and, again, does so by more than just using up an animal's time), then if it is habit-like, we would not expect simultaneous changes in other aspects of behavioural sequencing (changes should be specific to the ARB), while if dysfunction-related, we should see simultaneous changes across a whole suite of behaviours (see Section 4.3 above). A final, more tentative, feature of dysfunction-induced ARBs is that the primary environmental problem (e.g. premature loss of the mother) may be long past solving, but multiple enrichments may reduce the ARB, e.g. by reducing the stress that often precipitates bouts (cf. e.g. Novak et al., in press-b).

All the hypotheses above are probably best tested experimentally, in research-oriented settings. However, zoo data could still contribute to refining theses ideas and testing their generality.

\section{Discussion}

From this review, we can see that known or putative stereotypic behaviours are rather prevalent in zoos and similar institutions, at least in some captive wild species. We can also see that they always need to be taken seriously: empirically, the circumstances that induce them are typically linked with other signs of poor welfare, and there is also evidence that some may stem from C.N.S. dysfunction. Even when stereotypic behaviours help animals to cope with suboptimal environments, they are only expressed because more natural, and presumably more effective, activities are not possible. Overall, we therefore argue on both ethical and practical grounds that such activities should not be seen in zoos. Furthermore, merely 'explaining the behaviour away', taking an animal off exhibit, or physically preventing or punishing the behaviour-all responses that sometimes still occur to this day-are not appropriate: zoos do need to respond to ARBs, but not in ways likely to merely mask, or even exacerbate, animals' welfare problems.

Like many previous authors, we argue that the most welfare-friendly option is probably to provide appropriate enrichments, which the animal can choose to interact with (or not), and switch to using instead of stereotyping if it prefers to do so. However, given the evidently patchy and incomplete success of enrichments at reducing ARBs to date, we also suggest that their effectiveness could perhaps be enhanced via the positive reinforcement of non-stereotypic 
behaviours (or even, in the future, with pharmacological compounds such as anxiolytics, although not without considerably more background information than exists are present); while studies of companion animals also suggest that general measures to reduce stress could be helpful. Furthermore, cross-species comparisons may indicate the fundamental risk factors for $\mathrm{ARB}$, thence suggesting new environmental changes better able to target the root causes of problems. When the conservation value of some individuals or species is indirect rather than direct, then genetically selecting animals that are well-adapted to captivity could be a useful tactic too. Additionally, however, we clearly need more understanding of how enrichments act (or fail to), and also of the mechanisms that render different ARBs differentially easy to cure: throughout the preceding text, words like 'may', 'perhaps', 'could' and 'potentially' have all occurred with notable frequency, highlighting how speculative many of our suggestions are.

So, with limited fundamental knowledge, person-power and resources, at the present time how should zoos choose which animals to focus their enrichment attempts on? And how can they then tell if enrichment-use has been successful? Are changes in ARB, for example, enough to infer changes in welfare? And do failures to reduce ARB always indicate unimproved welfare? We have seen that environments that induce ARB are typically (but not always) poorer than those which do not, but that animals within such sub-optimal environments typically (but not always) fare better than non-stereotypic individuals. We also considered a range of ways in which ARBs may respond to enrichments, and shown that these do not always seem tightly correlated with welfare. Our review helps address these issues by suggesting specific properties of ARB and of other aspects of behaviour that could help identify the most at-risk individuals, and also by emphasising that reliable, valid welfare assessment requires far more than just data on the time spent in ARB: a variety of potential measures of stress and welfare exist, as do means of assessing how much animals value potential enrichments. Zoos need to exploit these more often and more thoroughly. Building better databases and conducting meta-analyses to identify at risk species, inherently poor husbandry-regimes and truly successful enrichments would also help make such decisions much easier for individual zoos in the future, as well as helping enrichments to be used pro-actively rather than reactively.

Finally, in this paper we emphasise that zoos can be valuable resources for increasing our understanding of how animals respond to captivity. The time and attention devoted to some zoo animals resulted in some of the very earliest hypotheses about ARBs (e.g. Hediger, 1950; MeyerHolzapfel, 1968), and in more recent times, quantitative studies of such behaviours and their relationships with husbandry-type, enrichment-provision and ecological niche have yielded insights with potential relevance to myriad other captive animals, beyond wild species in zoo situations. However, it is also clear that zoos are challenging places in which to do research: fundamental hypothesis-testing can be impeded by the variation between enclosures, small sample sizes, problems of non-independence between group members, and the understandable desire to reduce ARBs quickly rather than ascertain the niceties of underlying mechanisms (Swaisgood and Shepherdson, in press). We therefore hope that the behavioural problems evident in some zoo animals, combined with the very real desire of good zoos to eliminate these and to maximise welfare, together prompt more fundamental research elsewhere, in more controlled situations, that these institutions can then benefit from.

\section{Acknowledgments}

Thanks to the two referees who commented on the first draft; to Ron Swaisgood for excellent editorial input; to Joe Garner for enjoyable arguments about definitions; to Mollie Bloomsmith 
for references on training animals not to stereotype; to Kathy Carlstead for supplementary information that assisted Table 1; to Ron Keiper for sending hard-to-acquire papers; and to Janine Brown for discussion of the different (and fuller) approaches one may take to improve zoo animals' welfare when their conservation value is indirect. G. Mason was supported by a BBSRC David Phillips Fellowship followed by an NSERC Canada Research Chair; the Universities Federation for Animal Welfare funded Naomi Latham and Sophie Vickery for this work.

\section{References}

Ames, A., 1993. The behaviour of captive polar bears. UFAW Animal Welfare Research Report no. 5, Universities Federation for Animal Welfare.

Ames, A., 1994. The welfare and management of bears in zoological gardens. Universities Federation for Animal Welfare. UFAW Animal Welfare Research Report no. 7.

Barber, J., Shepherdson, D., in press. Enriching with SPIDER. Box 2 in Chapter 9. In: Mason, G., Rushen, J. (Eds.), Stereotypic Behaviour in Captive Animals: Fundamentals and Applications for Welfare, 2nd ed. CAB International, Wallingford.

Bashaw, M.J., Tarou, L.R., Maki, T.S., Maple, T.L., 2001. A survey assessment of variables related to stereotypy in captive giraffe and okapi. Appl. Anim. Behav. Sci. 73, 235-247.

Bassett, L., Buchanan-Smith, H.M., 2007. Effects of predictability on the welfare of captive animals. Appl. Anim. Behav. Sci. 102, 223-245.

Bergeron, R., Badnell-Waters, A., Lambton, S., Mason, G., in press. Stereotypic oral behaviour in captive ungulates: Foraging, diet and gastro-intestinal function. In: Mason, G., Rushen, J. (Eds.), Stereotypic Behaviour in Captive Animals: Fundamentals and Applications for Welfare, 2nd ed. CAB International, Wallingford.

Bloomsmith, M.A., Marr, M.J., Maple, T.L., 2007. Addressing nonhuman primate behavioral problems through the application of operant conditioning: Is the human treatment approach a useful model? Appl. Anim. Behav. Sci. 102, $205-222$.

Cabib, S., in press. The neurophysiology of stereotypy II-the role of stress. In: Mason, G., Rushen, J. (Eds.), Stereotypic Behaviour in Captive Animals: Fundamentals and Applications for Welfare, 2nd ed. CAB International, Wallingford.

Carlstead, K., 1991. Husbandry of the Fennec fox Fennecus zerda: environmental conditions influencing stereotypic behaviour. Int. Zoo Yrbk 30, 202-207.

Carlstead, K., Brown, J.L., Seidensticker, J., 1993. Behavioural and adrenocortical responses to environmental changes in leopard cats (Felis bengalensis). Zoo Biol. 12, 321-331.

Carlstead, K., 1998. Determining the causes of stereotypic behaviours in zoo carnivores: towards developing appropriate enrichment. In: Shepherdson, D.J., Mellen, J., Hutchins, M. (Eds.), Second Nature: Environmental Enrichment for Captive Mammals. Smithsonian Institution Press, Washington, pp. 172-183.

Carlstead, K., Shepherdson, D., 1994. Effects of environmental enrichment on reproduction. Zoo Biol. 13, 447458.

Carlstead, K., Mellen, J., Kleiman, D.G., 1999a. Black rhinoceros (Diceros bicornis) in US zoos. I. Individual behavior profiles and their relationship to breeding success. Zoo Biol. 18, 17-34.

Carlstead, K., Fraser, J., Bennett, C., Kleiman, D.G., 1999b. Black rhinoceros (Diceros bicornis) in U.S. zoos. II. Behavior, breeding success, and mortality in relation to housing facilities. Zoo Biol. 18, 35-52.

Clark, J.D., Huber, D., Servheen, C., 2002. Bear reintroductions: lessons and challenges. Ursus 13, 335-346.

Clubb, R., Mason, G., 2002. A Review of the Welfare of Zoo Elephants in Europe. RSPCA, Horsham, West Sussex, UK.

Clubb, R., Mason, G., 2003. Captivity effects on wide-ranging carnivores. Nature 425, 473-474.

Clubb, R., Mason, G., 2004. Pacing polar bears and stoical sheep: testing ecological and evolutionary hypotheses about animal welfare. In: Kirkwood, J.K., Roberts, E.A., Vickery, S. (Eds.), Proceedings of the UFAW International Symposium Science in the Service of Animal Welfare, 2003, vol. 13, Animal Welfare, Edinburgh, pp. S33-S40.

Clubb, R., Mason, G., 2007. Natural behavioural biology as a risk factor in carnivore welfare: How analysing species differences could help zoos improve enclosures. Appl. Anim. Behav. Sci. 102, 303-328.

Clubb, R., Vickery, S.S., in press. Locomotory stereotypies in carnivores: does pacing stem from hunting, ranging or frustrated escape? In: Mason, G., Rushen, J. (Eds.), Stereotypies in Captive Animals: Fundamentals and Applications for Welfare, 2nd ed. CAB International, Wallingford.

Cooper, J.J., Ödberg, F., Nicol, C.J., 1996. Limitations on the effectiveness of environmental improvement in reducing stereotypic behaviour in bank voles (Clethrionomys glareolus). Appl. Anim. Behav. Sci. 48, 237-248. 
Cooper, J.J., McDonald, L., Mills, D.S., 2000. The effects of increasing visual horizons on stereotypic weaving: implications for the social housing of stabled horses. Appl. Anim. Behav. Sci. 69, 67-83.

Dawkins, M.S., 1990. From an animal's point of view: motivation, fitness and animal welfare. Behav. Brain Sci. 13 , 1-61.

Dollinger, P., Baumgartner, R., Pagan, O., Wechsler, B., 1996. Husbandry and pathology of polar bears (Thalarctos maritimus) in Swiss zoos. In: European Association of Zoo and Wildlife Veterinarians (EAZWV) First Scientific Meeting, Rostock, Germany, May 16-18.

Douglas, M.W., Cunnick, J.E., Zimmerman, D.R., von Borrell, E.H., 1998. Impact of feeding regimen on behavioural and physiological indicators for feeding motivation and satiety. J. Anim. Sci. 76, 2589-2595.

Eaton, G.G., Kelley, S.T., Axthelm, M.K., Iliffsizemore, S.A., Shiigi, S.M., 1994. Psychological well-being in paired adult female rhesus (Macaca mulatta). Am. J. Primatol. 33, 89-99.

EC (European Commission), 2001. The Welfare of Animals Kept for Fur Production: Report of the Scientific Committee on Animal Health and Animal Welfare. Adopted on December 12-13, 2001.

Fentress, J.C., 1973. Specific and nonspecific factors in the causation of behavior. In: Bateson, P.P.G., Klopfer, P.H. (Eds.), Perspectives in Ethology, vol. 1. Plenum Press, London, pp. 155-218.

Fentress, J.C., 1976. Dynamic boundaries of patterned behaviour: interaction and self-organization. In: Bateson, P.P.G., Hinde, R.A. (Eds.), Growing Points in Ethology. Cambridge University Press, Cambridge, pp. 135-169.

Foley, J.P., 1934. First year development of a Rhesus monkey reared in isolation. J. Gen. Psychol. 45, 39-105.

Forthman, D.L., Bakeman, R., 1992. Environmental and social influences on enclosure use and activity patterns of captive sloth bears (Ursus ursinus). Zoo Biol. 11, 405-415.

Freeman, H., 1983. Behavior in adult pairs of captive snow leopards (Panthera uncia). Zoo Biol. 2, 1-22.

Garner, J., in press-a. Perseveration and stereotypy: systems-level insights from clinical psychology. In: Mason, G., Rushen, J. (Eds.), Stereotypic Behaviour in Captive Animals: Fundamentals and Applications for Welfare, 2nd ed. CAB International, Wallingford.

Garner, J., in press-b. Implications of recognising mechanistic differences in abnormal repetitive behaviour. Box 2, Chapter 10. In: Mason, G., Rushen, J. (Eds.), Stereotypic Behaviour in Captive Animals: Fundamentals and Applications for Welfare, CAB International, Wallingford.

Gould, E., Bres, M., 1986. Regurgitation and reingestion in captive gorillas: description and intervention. Zoo Biol. 5, 241-250.

Griffith, B., Scott, J.M., Carpenter, J.W., Reed, C., 1989. Translocation as a species conservation tool: status and strategy. Science 245, 477-480.

Haines, K., Hanes, M., 2004. Gerbil FAQ. http://members.nanc.com/ mhaines/gerbil.html\#section6.8 (accessed November 2005).

Hancocks, D., 1980. Bringing nature into the zoo: inexpensive solutions for zoo environments. Int. J. Study Anim. Problems 1, 170-177.

Hare, V.J., 1995. Behaviour modification of captive Alaska brown bears (Ursus arctos gyas) using automated food dispensers. In: Proceedings of the Second International Conference on Environmental Enrichment, Copenhagen Zoo, Frederiksberg, Denmark, pp. 39-61.

Hediger, H., 1950. Wild Animals in Captivity. Butterworths, London.

Hennessy, C.L., 1996. Reducing stereotypic behaviour in polar bears (Ursus maritimus) at Auckland Zoo. Ratel 23, 9-21.

Hogan, L., 2004. The Behaviour of Captive Common Wombats. Honours Thesis, University of Queensland, Australia. Ironmonger, J., 1992. The Good Zoo Guide. Harper \& Collins, London, pp. 43 and 68.

IUDZG (International Union of Directors of Zoological Gardens), 1993. The World Zoo Conservation Strategy: The Role of the Zoos and Aquaria of the World in Global Conservation. The World Zoo Organisation.

Irven, O., 1993. The decline of bears in British zoos. Int. Zoo News 40, 25-28.

Jensen, P., 1988. Diurnal rhythm of bar-biting in relation to other behaviour in pregnant sows. Appl. Anim. Behav. Sci. 21, 337-346.

Jeppesen, L.L., Falkenberg, H., 1990. Effects of play balls on pelt-biting, behaviour, and level of stress in ranch mink. Scientifur 14, 179-186.

Jordon-Owers, L., 2003. Homeopathy for stereotypic behaviour in bears. In: Proceedings of the Spring Meeting of the British Veterinary Zoological Society (BVZS), Dublin, Ireland.

Kastelein, R.A., Wiepkema, P.R., 1989. A digging trough as occupational therapy for Pacific walruses Odobenus rosmarus in human care. Aqu. Mamm. 15, 9-17.

Keiper, R.R., 1969. Causal factors of stereotypies in caged birds. Anim. Behav. 17, 114-119.

Keiper, R.R., 1970. Studies of stereotypy function in the canary (Serinus canarias). Anim. Behav. 18, $353-357$.

Keiper, R.R., 1975. Effect of differing feeding conditions on the development of spot-picking in the canary. Proc. Pennsylvania Acad. Sci. 49, 54-56. 
Kolter, L., 1995. Control of behaviour and the development of disturbed behaviour patterns. In: Gansloßer, U., Hodges, J.K., Kaumanns, W. (Eds.), Research and Captive Propagation. Finlander Verlag, Furth, pp. 248-255.

Kolter, L., Zander, R., 1995. Potential and limitations of environmental enrichment in managing behavioural problems of polar bears. In: Proceedings of the Second International Conference on Environmental Enrichment, Copenhagen Zoo, Frederiksberg Denmark, August 21-25, pp. 131-141.

Lashley, K.S., 1921. Studies of cerebral function in learning. II. The effects of long-continued practice upon cerebral localisation. J. Comp. Psychol. 1, 453-468.

Latham, N., Mason, G.L., 2006. Maternal separation and the development of stereotypies: a review. Appl. Anim. Behav. Sci. (in press).

Latham, N., Würbel, H., in press. Wheel running: a common rodent stereotypy? Box 2, Chapter 4. In: Mason, G., Rushen, J. (Eds.), Stereotypic Behaviour in Captive Animals: Fundamentals and Applications for Welfare, 2nd ed. CAB International, Wallingford.

Laule, G., 1993. The use of behavioral management techniques to reduce or eliminate abnormal behaviour. Anim. Welfare Inf. Center Newslett. 4, 8-11.

Lewis, M.H., Presti, M.F., Lewis, J.B., Turner, C.A., in press. The neurobiology of stereotypy. I. Environmental complexity. In: Mason, G., Rushen, J. (Eds.), Stereotypic Behaviour in Captive Animals: Fundamentals and Applications for Welfare, 2nd ed. CAB International, Wallingford.

Lindberg, A.C., Nicol, C.J., 1997. Dust-bathing in modified battery cages: is sham dustbathing an adequate substitute? Appl. Anim. Behav. Sci. 55, 113-128.

Magin, C.D., Johnson, T.H., Groombridge, B., Jenkins, M., Smith, H., 1994. Species extinctions, endangerment and captive breeding. In: Olney, P.J.S., Mace, G.M., Feistner, A.T.C. (Eds.), Creative Conservation: Interactive management of wild and captive animals. Chapman \& Hall, London, pp. 19-31.

Markowitz, H., Schmidt, M.J., Moody, A., 1978. Behavioural engineering and animal health in the zoo. Int. Zoo Yrbk 18, 190-194.

Mallapur, A., Cheelam, R., 2002. Environmental influences on stereotypy and the activity budget of Indian leopards (Panthera pardus) in foru zoos in southern India. Zoo Biol. 21, 585-595.

Mallapur, A., Waran, N., Sinha, A., 2005. Factors influencing the behaviour and welfare of captive lion-tailed macaques in Indian zoos. Appl. Anim. Behav. 91, 337-353.

Marriner, L.M., Drickamer, L.C., 1994. Factors influencing stereotyped behavior of primates in a zoo. Zoo Biol. 13, 267275.

Mason, G.J., 1991a. Stereotypies: a critical review. Anim. Behav. 41, 1015-1037.

Mason, G.J., 1991b. Stereotypies and suffering. Behav. Process 25, 103-115.

Mason, G.J., 1993. Age and context affect the stereotypies of caged mink. Behav. Process 127, 191-229.

Mason, G., in press-a. Stereotypic behaviour in captive animals: fundamentals, and implications for welfare and beyond. In: Mason, G., Rushen, J. (Eds.), Stereotypic Behaviour in Captive Animals: Fundamentals and Applications for Welfare, 2nd ed. CAB International, Wallingford.

Mason, G., in press-b. Are wild-born animals 'protected' from stereotypy when placed in captivity? Box 1, Chapter 7. In: Mason, G., Rushen, J. (Eds.), Stereotypic Behaviour in Captive Animals: Fundamentals and Applications for Welfare, 2nd ed. CAB International, Wallingford.

Mason, G., Cooper, J., Clarebrough, C., 2001. Frustrations of fur-farmed mink. Nature 410, 35-36.

Mason, G., Cooper, J., Clarebrough, C., 2002. The use of techniques from human economics to measure what animals value, illustrated by experimental work on the American mink, Mustela vison. In: Hare, V.J., Worley, K.E., Myers, K. (Eds.), Proceedings of the Fourth International Conferences on Environmental Enrichment. The Shape of Enrichment Inc., San Diego, pp. 111-117.

Mason, G.J., Latham, N.R., 2004. Can't stop, won't stop: is stereotypy a reliable animal welfare indicator. In: Kirkwood, J.K., Roberts, E.A., Vickery, S. (Eds.), Proceedings of the UFAW International Symposium Science Service Animal Welfare, vol. 13, Edinburgh 2003, Anim. Welfare 13, S57-S69.

Mason, G.J., Rushen, J., in press. Stereotypic Behaviour in Captive Animals: Fundamentals and Applications for Welfare, 2nd ed. CAB International, Wallingford.

May, R.M., Lyles, A.M., 1987. Conservation biology: living Latin binomials. Nature 326, 642-643.

Mechner, F., 1995. Learning and Practicing Skilled Performance. The Mechner Foundation, New York.

Meehan, C.L., Garner, J.P., Mench, J.A., 2003. Isosexual pair housing improves the welfare of young Amazonian parrots. Appl. Anim. Behav. Sci. 81, 73-88.

Mellen, J.D., 1991. Factors influencing reproductive success in small captive exotic felids (Felis spp.) —a multipleregression analysis. Zoo Biol. 10, 95-110. 
Mellen, J., Hayes, M., Shepherdson, D., 1998. Captive environments for small felids. In: Shepherdson, D., Mellen, J., Hutchins, M. (Eds.), Second Nature: Environmental Enrichment for Captive Animals. Smithsonian Institution Press, Washington, pp. 184-201.

Meyer-Holzapfel, M., 1968. Abnormal behaviour in zoo animals. In: Fox, M.W. (Ed.), Abnormal Behaviour in Animals. Saunders, London, pp. 476-503.

Mills, A., Duncan, I., Slee, G., Clarke, J., 1985b. Heart rate and laying behaviour in two strains of domestic chicken. Physiol. Behav. 35, 145-147.

Mills, A., Wood-Gush, D., Hughes, B, 1985a. Genetic analysis of strain differences in pre-laying behaviour in battery cages. Br. Poult. Sci. 26, 187-197.

Mills, D., Luescher, L., in press. Veterinary and pharmacological approaches to abnormal repetitive behaviour. In: Mason, G., Rushen, J. (Eds.), Stereotypic Behaviour in Captive Animals: Fundamentals and Applications for Welfare, 2nd ed. CAB International, Wallingford.

Morgan, K.N., Tromborg, C.T., 2007. Sources of stress in captivity. Appl. Anim. Behav. Sci. 102, $262-302$.

Morris, D., 1964. The response of animals to a restricted environment. Symp. Zool. Soc. Lond. 13, 99-120.

NAS (National Autistic Society), 2002. Living with Autism-Basic Guidelines for Parents and Carers Dealing with Children with Autistic Spectrum Disorder (ASD). Available at: http://www.nas.org.uk/family/parents/dealing.html (accessed September 2003).

Nevison, C.M., Hurst, J.L., Barnard, C.J., 1999a. Why do male ICR(CD-1) mice perform bar-related (stereotypic) behaviour? Behav. Process 47, 95-111.

Nevison, C.M., Hurst, J.L., Barnard, C.J., 1999b. Strain-specific effects of cage enrichment in male laboratory mice (Mus musculus). Anim. Welfare 8, 361-379.

Norman, D.A., 1981. The categorization of action slips. Psychol. Rev. 89, 1-55.

Novak, M.A., Bollen, K.S., in press. Differences in the prevalence and form of abnormal behaviour across primates. Box 3, Chapter 3. In: Mason, G., Rushen, J. (Eds.), Stereotypic Behaviour in Captive Animals: Fundamentals and Applications for Welfare, 2nd ed. CAB International, Wallingford.

Novak, M.A., Meyer, J.S., Lutz, C., Tiefenbacher, S., in press-a. Social deprivation and social separation: developmental insights from primatology. In: Mason, G., Rushen, J. (Eds.), Stereotypic Behaviour in Captive Animals: Fundamentals and Applications for Welfare, 2nd ed. CAB International, Wallingford.

Novak, M.A., Meyer, J.S., Lutz, C., Tiefenbacher, S., in press-b. Stress and the performance of primate stereotypies. Box 3, Chapter 8. In: Mason, G., Rushen, J. (Eds.), Stereotypic Behaviour in Captive Animals: Fundamentals and Applications for Welfare, 2nd ed. CAB International, Wallingford.

Novak, M.A., Meyer, J.S., Lutz, C., Tiefenbacher, S., Gimpel, J., Mason, G., in press-c. The effects of enrichment in biomedical facilities: some insights into their effects on laboratory primates' stereotypies. Box 3, Chapter 9. In: Mason, G., Rushen, J. (Eds.), Stereotypic Behaviour in Captive Animals: Fundamentals and Applications for Welfare, 2nd ed. CAB International, Wallingford.

Ödberg, F.O., in press. Is it ethical to physically prevent horses performing oral stereotypies? Box 3, Chapter 2. In: Mason, G., Rushen, J. (Eds.), Stereotypic Behaviour in Captive Animals: Fundamentals and Applications for Welfare, 2nd ed. CAB International, Wallingford.

Olsson, I.A.S., Keeling, L.J., Duncan, I.J.H., 2002. Why do hens sham dust-bathe when they have litter? Appl. Anim. Behav. Sci. 76, 53-64.

Owen, M.A., Swaisgood, R.R., Czekala, N.M., 2005. Enclosure choice and well-being in giant pandas: is it all about control? Zoo Biol. 24, 475-481.

Poulsen, E.M.B., Honeyman, V., Valentine, P.A., Teskey, G.C., 1996. Use of fluoxetine for the treatment of stereotypical pacing behavior in a captive polar bear. J. Am. Vet. Med. Assoc. 209, 1470-1474.

Poulsen, E.M.B., Hutchinson, J., Honeyman, V., Cooper, R., Teskey, G., 1998. Using enrichment as a diagnostic tool in one captive polar bear. In: Proceedings of the Third International Conference on Environmental Enrichment, Shape Enrich, Orlando, FL, USA, October 12-17, pp. 215-257.

Poulsen, E.M.B., Teskey, G.C., in press. Pacing, Prozac and a Polar Bear. Box 4, Chapter 10. In: Mason, G., Rushen, J. (Eds.), Stereotypic Behaviour in Captive Animals: Fundamentals and Applications for Welfare, 2nd ed. CAB International, Wallingford.

Rowe, W.B., Spreekmeester, E., Meaney, M.J., Quirion, R., Rochford, I., 1998. Reactivity to novelty in cognitivelyimpaired and cognitively unimpaired aged rats and young rats. Neuroscience 83, 669-680.

Schofield, W., Mulville, J., 1998. Assessment of the modified Forsell's procedure for the treatment of oral stereotypies in 10 horses. Vet. Rec. 142, 572-575.

Shabani, D.B., Wilder, D.A., Flood, W.A., 2001. Reducing stereotypic behavior through discrimination training, differential reinforcement of other behavior, and self-monitoring. Behav. Intervent. 16, 279-286. 
Shepherdson, D.J., Mellen, J.D., Hutchins, M., 1998. Second Nature: Environmental Enrichment for Captive Mammals. Zoo and Aquarium Biology and Conservation Series. Smithsonian Institution Press, Washington.

Shepherdson, D., Carlstead, K.C., Wielebnowski, N., 2004. Cross institutional assessment of stress responses in zoo animals using longitudinal monitoring of faecal corticoids and behaviour. In: Kirkwood, J.K., Roberts, E.A., Vickery, S. (Eds.), Proceedings of the UFAW International Symposium Science Service Animal Welfare, Edinburgh 2003, Anim. Welfare 13, 13.

Shyne, A., in press. A meta-analysis on the effects of environmental enrichment in zoo animals. Zoo Biol. (published online: July 2006).

Swaisgood, R.R., Shepherdson, D.J., 2005. Scientific approaches to enrichment and stereotypies in zoo animals: what's been done and where should we go next? Zoo Biol. 24, 499-518.

Swaisgood, R.R., Shepherdson, D.J., in press. Environmental enrichment as a strategy for mitigating stereotypies in zoo animals: a literature review and meta-analysis. In: Mason, G., Rushen, J. (Eds.), Stereotypic Behaviour in Captive Animals: Fundamentals and Applications for Welfare, 2nd ed. CAB International, Wallingford.

Tarlow, E.M., Blumstein, D.T., 2007. Evaluating methods to quantify anthropogenic stressors on wild animals. Appl. Anim. Behav. Sci. 102, 429-451.

Tarou, L.R., Bashaw, M.J., Maple, T.L., 2003. Failure of a chemical spray to significantly reduce stereotypic licking in a captive giraffe. Zoo Biol. 22, 601-607.

Tarou, L.R., Bloomsmith, M.A., Maple, T.L., 2005. Survey of stereotypic behaviours in prosimians. Am. J. Primatol. 65, 81-196.

Templin, R., 1993. Stereotypic movements in zoo animals. In: Proceedings of the International Congress on Applied Ethology, Humboldt University, Berlin, Germany, pp. 54-59.

Tinbergen, N., 1951. The Study of Instinct. Oxford University Press, Oxford.

Turner, M., 1999a. Generating novel ideas: fluency performance in high-functioning and learning disabled individuals with autism. J. Child Psychol. Psych. 40, 189-201.

Turner, M., 1999b. Annotation: repetitive behaviour in autism: a review of psychological research. J. Child Psychol. Psych. 40, 839-849.

Uchida, Y., Dodman, N.H., DeGhetto, D., 1998. Animal behavior case of the month. J. Am. Vet. Med. Assoc. 212, 354355.

van Keulen-Kromhout, G., 1976. Captivity behaviour of bears (Ursidae): an investigation of the influences of the enclosure on behaviour and conditions in captive bears. Artis Special Inf. 2, 1-61.

Vickery, S.S., 2003. Stereotypy in Caged Bears: Individual and Husbandry Factors. Ph.D. Thesis, University of Oxford, UK.

Vickery, S.S., Mason, G.J., 2003. Behavioural persistence in captive bears: implications for reintroduction. Ursus 14, 3543.

Vickery, S.S., Mason, G.J., 2005. Behavioural persistence in captive bears: a reply to Criswell and Galbreath. Ursus 16 , 274-279.

Vinke, C.M., Eenkhoorn, N.C., Netto, W.J., Fermont, P.C.J., Spruijt, B.M., 2002. Stereotypic behaviour and tail biting in farmed mink (Mustela vison) in a new housing system. Anim. Welfare 11, 231-245.

Watters, J.V., Meehan, C.L., 2007. Different strokes: can managing behavioral types increase post-release success. Appl. Anim. Behav. Sci. 102, 364-379.

WAZA (World Association of Zoos and Aquariums), 2005. The World Zoo Conservation Strategy: Building a Future for Wildlife. World Aquaria and Zoos Association Executive Office, Bern.

Widholzer, F.L., Voss, W.A., 1978. Breeding the giant anteater, Myrmecophaga tridactyla, at the Sao Paulo Zoo. Int. Zoo Yrbk 18, 122-123.

Wiedenmayer, C., 1997. Causation of the ontogenetic development of stereotypic digging in gerbils. Anim. Behav. 53, $461-470$.

Würbel, H., Bergeron, R., Cabib, S., in press. The coping hypothesis of stereotypic behaviour. Box 3, Chapter 1, In: Mason, G., Rushen, J. (Eds.), Stereotypic Behaviour in Captive Animals: Fundamentals and Applications for Welfare, 2nd ed. CAB International, Wallingford.

Young, R., 2003. Environmental Enrichment. Blackwell Science, Oxford. 